\title{
RESPUESTA PARADÓJICA AL MANEJO ANTITUBERCULOSO EN UN PACIENTE SIN INFECCIÓN POR VIH: REPORTE DE CASO.
}

\section{María Alejandra Izquierdo Orozco, Izquierdo MA, Lutz JR, Méderi Galindo JL,} Méderi Morales AS, Carrillo JA

\section{INTRODUCCIÓN}

La tuberculosis es una enfermedad infecciosa de interés público por su impacto a nivel mundial lo que ha llevado a establecer lineamientos de tratamiento claros que incluyen un manejo estandarizado. El desarrollo de una reacción paradójica al antituberculoso es una complicación no sospechada pero potencialmente fatal que suele ser más frecuente en los pacientes con infección por VIH.

\section{OBEJETIVO}

Describir el caso de un paciente con diagnóstico de tuberculosis pulmonar quien presentó una respuesta paradójica al tratamiento antituberculoso (Tuberculosis miliar).

\section{MATERIAL Y MEDOTOS}

Descripción de un caso y revisión no sistemática de la literatura médica utilizando los siguientes términos: "Tuberculosis" AND "immune reconstitution" OR "immune reconstitution inflammatory syndrome".

\section{RESULTADOS}

Se describe el caso de un paciente de 47 años, de sexo masculino, que consultó por fiebre asociada con disuria, poliaquiuria y lesiones descamativas en la piel, con antecedente de lupus eritematoso sistémico en tratamiento con prednisolona, cloroquina y micofenolato. Durante la hospitalización presentó tos y disnea. La tomografía mostró una consolidación pulmonar en cuña y nódulos centrilobulillares. La angiotomografía de tórax descartó tromboembolismo pulmonar. La broncoscopia diagnóstica más toma de lavado broncoalveolar tuvo pruebas microbiológicas iniciales negativas. Se realizó biopsia pulmonar que mostró bacilos acidoalcohol resistentes por lo que se inició tratamiento con Isoniazida, Rifampicina, Pirazinamida, Etambutol y macrólido egresando del hospital con este tratamiento. Reingresó adespués de un mes por episodios de emesis. El paciente refirió adecuada adherencia a la terapia ordenada hasta ese momento. La radiografía de tórax y tomografía de tórax mostraron múltiples micronódulos de distribución aleatoria en patrón miliar. Se llevó a biopsia pulmonar abierta que mostró macroscópicamente una consistencia micronodular y en la patología se observaron bacilos acido alcohol resistentes. Se sospechó multidrogorresistencia pero las pruebas de sensibilidad descartaron esta hipótesis. El paciente recibió manejo para sus complicaciones, continuó con antituberculosos y esteroide por la enfermedad de base, con mejoría clínica y posterior egreso. La reacción paradójica a los antituberculosos se define como un deterioro clínico y/o imagenológico, o la aparición de nuevas lesiones en pacientes con medicación dirigida para tuberculosis, con una mejoría inicial de los sintomas (2). Puede estar presente hasta en un $30 \%$ de la población tratada por tuberculosis y clásicamente se ha relacionado a pacientes infectados por VIH(2). Otros factores de riesgo asociados son linfopenia por otras causas y la inmunosupresión farmacológica. La fisiopatología sugerida propone como causa la recuperación del sistema inmune durante el transcurso del tratamiento por una respuesta inflamatoria exagerada que empeora el daño tisular secundario a la infección por tuberculosis asi como la muerte rápida de las micobacterias que produce una liberación de componentes microbianos que estimulan una gran respuesta inflamatoria. Los hallazgos clínicos y radiológicos son muy variables y suelen responder al manejo sintomático. En casos graves, se podría usar prednisolona (3)

\section{CONCLUSIONES}

- La reacción paradójica al manejo antituberculoso es una respuesta inflamatoria que puede estar presente hasta en un $30 \%$ de los pacientes y se debe sospechar en aquellos que posterior a iniciar el manejo antituberculoso y presentar una mejoría inicial. • El desarrollo de una diseminación hematógena como manifestación de una reacción paradójica al manejo antituberculoso en un paciente con tuberculosis pulmonar no es frecuente y representa un hallazgo inusual inesperado y sin casos encontrados en la literatura médica de acuerdo a la revisión realizada. • La presentación de una respuesta paradójica a los antifímicos solo puede confirmarse después de descartar otras causas de deterioro clínico y resistencia a los antimicrobianos por parte de la micobacteria. Adjuntos:figura-1.pngFigura-2.pngFigura-3.png

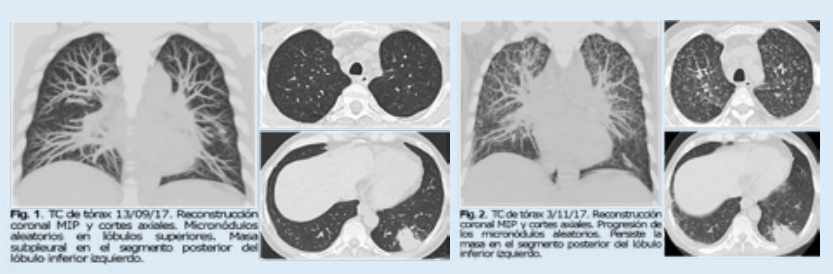

